\title{
Less Use of the Bipolar Cautery can Prevent Postlaminectomy Epidural Fibrosis: An Experimental Study in Rats
}

\author{
Vaner KOKSAL ${ }^{1}$, Tolga MERCANTEPE², Levent TUMKAYA², Ibrahim Suat OKTEM ${ }^{3}$ \\ ${ }^{1}$ University of Health Sciences, Samsun Health Practices and Research Center, Department of Neurosurgery, Samsun, Turkey \\ ${ }^{2}$ Recep Tayyip Erdogan University, School of Medicine, Department of Histology and Embryology, Rize, Turkey \\ ${ }^{3}$ Erciyes University, School of Medicine, Department of Neurosurgery, Kayseri, Turkey
}

This study has been presented as an oral presentation at the $32^{\text {nd }}$ National Congress of Turkish Neurosurgery Society between 20 and 24 April 2018 at Antalya, Turkey.

Corresponding author: Vaner KOKSAL vanerkoksal@hotmail.com

\section{ABSTRACT}

AIM: To investigate the role of bipolar electrocautery in the occurrence of epidural fibrosis following lumbar spine laminectomy in a rat model.

MATERIAL and METHODS: Fourteen male Sprague-Dawley rats (age: 4-6 months, weight: 250-300 g) were randomly divided into two groups, a bipolar group (Group I) and a control group (Group II). Laminectomy was performed between the L1 and L3 levels. In Group I ( $n=7)$, a laminectomy was carried out and soft tissue around the spinal cord was coagulated by using a bipolar electrocautery. In the control group $(n=7)$, only laminectomy was performed. The animals were sacrificed 4 weeks after surgery, and post-laminectomy epidural fibrosis (PLEF) was evaluated. Macropathological, qualitative and quantitative histological evaluations as well as immunohistochemical staining including transforming growth factor- $\beta$ (TGF- $\beta$ ), collagen I and collagen III were performed.

RESULTS: The numbers of TGF- $\beta$ positive cells staining (PCS) were $3.00 \pm 0.46$ for Group I and $1.00 \pm 0.52$ for Group II. The numbers of collagen I PCS were $2.00 \pm 0.93$ for Group I and $1.25 \pm 0.46$ for Group II. The numbers of collagen III PCS were 2.25 \pm 0.76 for Group I, $1.25 \pm 0.46$ for Group II, and TGF- $\beta$ PCS than Group II ( $\leq 0.05)$. Compared with the control group, Group I's formation of epidural fibrosis was significantly increased.

CONCLUSION: Our study clearly demonstrated that the use of bipolar cauterisation is associated with increased PLEF in the experimental animal model. Thus, limiting the use of bipolar cauterisation may be effective in reducing this complication.

KEYWORDS: Bipolar cauterisation, Epidural fibrosis, Failed back syndrome, Post-laminectomy, Thermal damage, Rat

\section{INTRODUCTION}

S urgery for lumbar disc herniation $(\mathrm{LDH})$ is one of the most common procedures in spine surgery. In these procedures, a limited laminectomy is adopted to reach the disc herniation. The adhesion of the exposed neural tissue to the periphery due to excessive scar tissue is an undesirable complication that leads to the development of chronic pain complaints after surgery $(6,8,16)$. The development of such chronic complaints may be described as failed back syndrome (FBS) or post-laminectomy epidural fibrosis (PLEF) (25). Although the underlying causes of PLEF are still under investigation, PLEF remains a major cause of poor results in spinal surgery. For this reason, several in vivo and in vitro experimental studies have been undertaken or are in progress for preventing or reducing persistent complaints related to back pain $(1,9)$. Unfortunately, the results of these studies are not highly promising (33). In addition, it is still difficult to treat patients with established PLEF $(1,9,19,21)$. 
The inability to find a clear solution to the problem of PLEF has led to the questioning of the routine surgical technique; moreover, it gave rise to the idea for conducting this study. Haemostasis is essential during spine surgery because uncontrolled haemorrhage can lead to catastrophic complications; however, the effect of the method of haemostasis on PLEF remains unclear $(3,23,28)$. The present study aims at investigating the role of bipolar cauterisation in the pathogenesis of PLEF in a rat model.

\section{MATERIAL and METHODS}

\section{Ethical Statement}

The ethical approval for this study was obtained from the Recep Tayyip Erdogan University local ethics committee for animal experiments before the study (Decision no: 2015/49, Date: 30.07 .2015$)$. All applicable international, national and/ or institutional guidelines for the care and use of animals were followed. All the procedures performed in studies involving animals were in accordance with the ethical standards of the institution or laboratory at which the studies were conducted. The issued letter of this decision (2015/49) can be presented on reasonable request.

\section{Experimental Animals}

Fourteen male Sprague-Dawley rats, aged 4-6 months and weighing 250-300 g, were provided by the university animal care and research unit. The animals received care according to the criteria outlined in the 'Guide for the care and use of laboratory animals' prepared by the National Academy of Sciences and published by the National Institutes of Health.

\section{Study Design}

The rats were randomly divided into two groups of seven subjects each ( $n=7$, total: 14$)$, specifically, a bipolar group (Group I) and control group or non-bipolar group (Group II). The animals were kept under a constant temperature $(21 \pm$ $3^{\circ} \mathrm{C}$ ) and photoperiod (12 hours light/dark cycle). During the experimental period, all the subjects were fed ad libitum with pellets containing $21 \%$ crude protein (Purina) and had access to regular drinking water. The two groups were homogeneous in terms of their biological and physiological characteristics.

\section{Experimental Procedures}

The experiment was started under general anaeshesia, which was induced by ketamine hydrochloride $(25 \mathrm{mg} / \mathrm{kg}$; Ketalar; Pfizer, Istanbul, Turkey) and xylazine (5 mg/kg; Rompun; Bayer, Istanbul, Turkey) intramuscularly. The rats were placed in the prone position, and their backs were shaved. The surgical field was sterilised with povidone-iodine (Batticon; Adeka Pharmaceuticals Istanbul, Turkey). A median skin and dorsal fascia incision were performed from the Th12 to L4 vertebrae. The paravertebral muscles were dissected bilaterally over the laminae. An L1-L3 total laminectomy (TL) was performed using loop glasses with sharp, small-tip instruments $(19,35)$. In the two groups, the surgical area was irrigated with serum saline for 5 minutes. The bleeding stopped in this process. However, in a few rats, the washing time was extended when the bleeding did not stop. Additional haemostatic agents were not used. Bipolar cauterisation was used in Group I, while it was not used in Group II. Good haemostasis was always achieved before wound closure.

The LCS-EK601 system was set to soft coagulation mode for the bipolar cauterisation. The effect level of the device was set at the maximum output of $40 \mathrm{~W}$. In Group I ( $n=7)$. TL was carried out, and the soft tissue around the dural sac was burned with the bipolar cauterisation until carbonisation within 3-5 minutes (7). Attention was paid to avoid traumatising the dura and nerve roots. The skin and fascia were closed with non-absorbable suture material. The animals were kept alive in separate cages. Four weeks (28 days) after the surgery, the animals were sacrificed by administration of a lethal dose of ketamine hydrochloride. The vertebral column from Th12 to L4 was resected in en-bloc fashion, including the paraspinal muscles and epidural scar tissue (15).

\section{Histological Analysis (Preparation of Specimens)}

In all groups, the spinal cord tissues of the rats were given code numbers and put into bottles containing 10\% neutral formaldehyde. Seventy-two hours after sacrifice, the following process was applied for the tissues: dehydration in an increased alcohol series, clearing through a xylene series, immersion in liquid paraffin, and embedding in paraffin blocks. From the paraffin blocks of each rat, four $5-\mu \mathrm{m}$ serial sections with intervals of $50 \mu \mathrm{m}$ were taken using a microtome (Leica RM2125RT, Nussloch, Germany).

The obtained sections were brought from deparaffinisation to water and stained with haematoxylin and eosin (H\&E). Later on, the cover-slipped sections were photographed with a camera attached light microscope (Nikon Eclipse E600, Japan). Management of the same light settings was performed for photographing, especially in the histochemical analysis, for permitting unbiased evaluation $(26,31)$.

\section{Immunohistochemical (IHC) Staining and Analysis}

Specimens were tested for transforming growth factor- $\beta$ (TGF- $\beta$ ), collagen I and collagen III as follows: The sections were deparaffinised and treated with proteinase $\mathrm{K}$ solution (20 $\mathrm{\mu g} / \mathrm{mL}$ in phosphate-buffered saline [PBS]), washed in distilled water and immersed in 3\% hydrogen peroxide. After several washes with PBS, the sections were immersed in an equilibration buffer. The sections were incubated with TGF- $\beta$ (1:200, mouse monoclonal [2Ar2] to TGF beta 1, Abcam, UK), collagen I (1:100, mouse monoclonal to collagen I, Abcam) and collagen III (1:200, rabbit polyclonal to active collagen III, Abcam). After several washes, all the sections were incubated in anti-digoxigenin peroxidase. The sections were incubated with a mouse and rabbit specific HRP/DAB detection immunohistochemistry (IHC) kit (rabbit monoclonal, Abcam). The reaction was revealed with $0.06 \%$ 3,3-diaminobenzidine tetrahydrochloride (Sigma Chemical, St. Louis, MO) in PBS, and the sections were counterstained with Antibody Diluent (Abcam).

\section{Semi-Quantitative Analysis}

Histopathological and histochemical investigations were 
carried out using a light microscope. Every rat section was semi-quantitatively scored. For each section, five microscopic areas, representing nearly $100 \mu \mathrm{m}^{2}$, were selected randomly by two blinded histopathologists. The TGF- $\beta$, collagen I and collagen III positive cell densities in the degeneration area were calculated with an objective of $10 x$. The median of the histochemical evaluation was scored semi-quantitatively. The scoring was labelled based on the percentage of TGF- $\beta$-, collagen I-and collagen III-positive cells as follows: none $=-$, mild $=+$, moderate $=++$, severe $=+++$ and very severe $=++++$ (Table I) (15).

\section{Statistical Analysis}

Statistical analysis of the mean areas of the TGF- $\beta$, collagen I and collagen III positive cell density scores of all the groups was performed using the appropriate statistical methods. Comparisons of the valid TGF- $\beta$, collagen I and collagen III positive cell density scores among the two groups (groups I and II) were analysed using the Mann-Whitney $U$ test, and the numerical data of the groups were assessed. (A p-value $\leq 0.05$ was defined as significant). The values were determined as medians \pm standard deviations.

\section{RESULTS}

\section{Histological Results}

In the specimens from group I, haemostasis, oedematous area and fibrosis were observed (Figure 1A). In the specimens from group II, haemostasis with the oedematous area was highlighted (Figure 1B), as well as neutrophil cell infiltrations to connective tissue with large blood vessels that were congested and dilated (Figure 1B). However, fibrosis was not observed (Figure 1B).

\section{IHC Staining and Statistical Results}

TGF- $\beta$ labelling revealed an absence of cell staining in both groups (Figure 2A, B) and PCS in groups I (Figure 2A) and II (Figure 2B). The numbers of cells with TGF- $\beta$ PCS were 3.00 \pm 0.46 for group I and $1.00 \pm 0.52$ for group II $(p<0.05$, Table
I, Figure 3A). Collagen I labelling revealed an absence of cell staining in both groups (Figure 4) and PCS in groups I (Figure 4A) and II (Figure 4B). The numbers for collagen I PCS were $2.00 \pm 0.93$ for group I and $1.25 \pm 0.46$ for group II $(p<0.05$, Table II, Figure 3B). The numbers of collagen III PCS were 2.25 \pm 0.76 for group I (Figure $5 \mathrm{~A}$ ) and $1.25 \pm 0.46$ for group II (Figure 5B; $p<0.05$, Table III, Figure $3 C$ ).

Table I: IHC Positivity Score

\begin{tabular}{ll}
\hline Score & Results \\
\hline $\mathbf{0}$ & None \\
\hline $\mathbf{1}$ & Mild (less than 5\%) \\
\hline $\mathbf{2}$ & Moderate (involvement 5\%-25\%) \\
\hline $\mathbf{3}$ & Severe (more than \%25-50) \\
\hline $\mathbf{4}$ & Very severe (more than \%50) \\
\hline
\end{tabular}

Table II: Assessments of TGF- $\beta$ Positivity Scores of All Groups

\begin{tabular}{lc}
\hline Groups & $\begin{array}{c}\text { TGF- } \boldsymbol{\beta} \text { positivity scores } \\
\text { (Median } \pm \text { Std. Dev.) }\end{array}$ \\
\hline Group 1 & $3 \pm 0.46$ \\
\hline Group 2 & $1 \pm 0.52^{\mathrm{a}}$ \\
\hline
\end{tabular}

$a_{p \leq 0.05 \text { versus Group } 1 .}$

Table III: Assessments of Collagen-I Positivity Scores of All Groups

\begin{tabular}{lc}
\hline Groups & $\begin{array}{c}\text { Collagen-I positivity scores } \\
\text { (Median } \pm \text { Std. Dev.) }\end{array}$ \\
\hline Group 1 & $2.00 \pm 0.93$ \\
\hline Group 2 & $1.25 \pm 0.46^{\mathrm{a}}$ \\
\hline
\end{tabular}

$a_{p \leq 0.05 \text { versus Group } 1 .}$
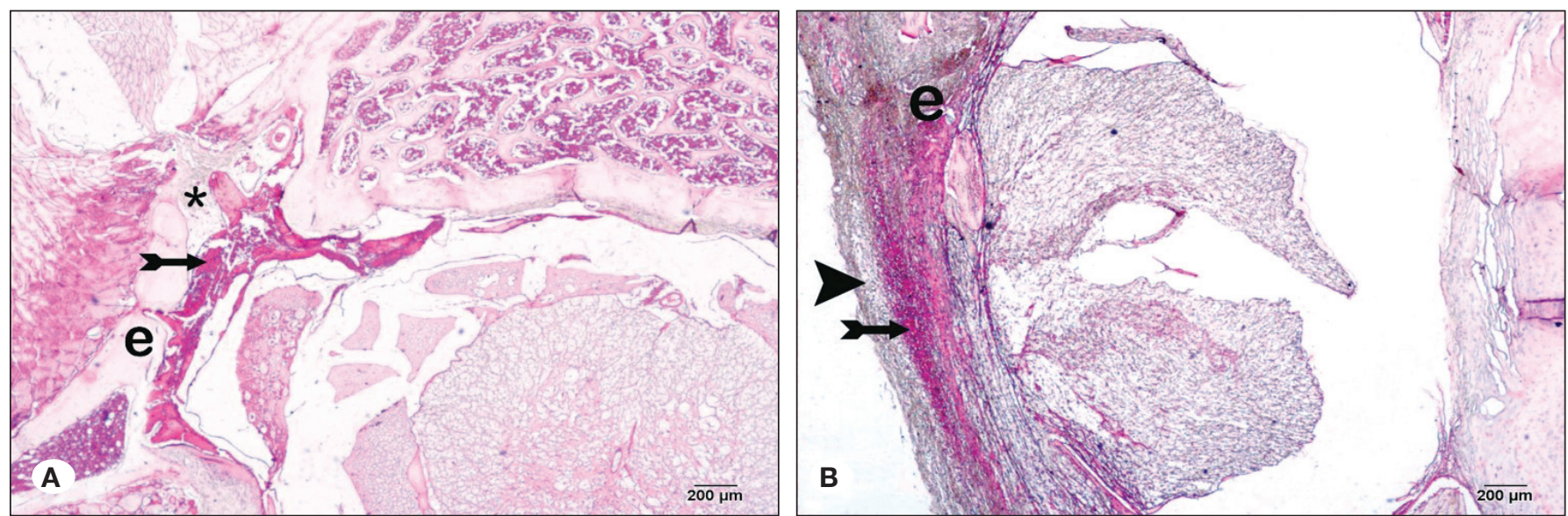

Figure 1: Light microscope image of spinal cord structure (Haematoxylin and Eosin, 40x). A) Group I. B) Group II. Haemostasis area of the spinal cord (tailed arrow). Oedema (e). Fibrillation (asterisk). Degenerative cells (arrowhead). 


\section{Adverse Events}

Due to narrow spinal diameters, paraparesis occurred during laminectomy in one animal per group. They were alive for 4 weeks although they had partial paralysis of the posterior limbs. However, no significant haemorrhage was observed in either group during surgery, and especially, there was no haemostasis problem without bipolar cautery in group II.

\section{DISCUSSION}

Postoperative fibrosis is a common consequence of every surgery, and it may become clinically relevant after spine surgery (29). The main cause of PLEF can be attributed to fibroblasts spreading into the epidural spaces during operation from the surface of the paravertebral muscles, from the fibrous layer of the periosteum and through post-operative
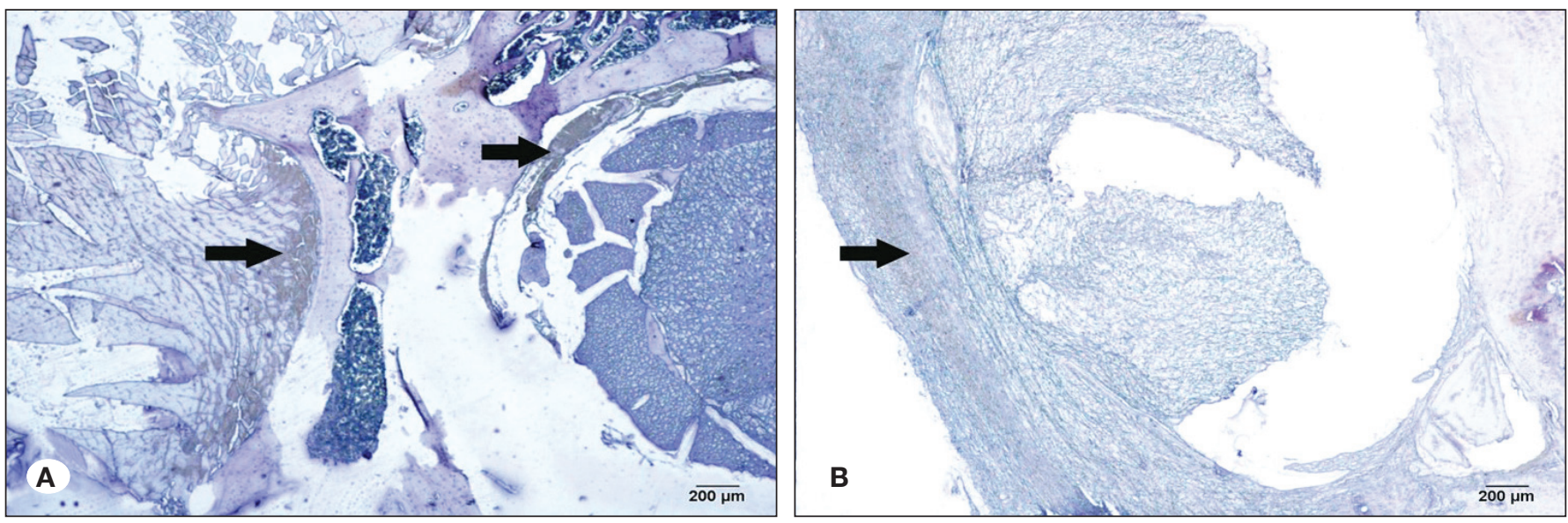

Figure 2: Photographs of rat spinal cords immunohistochemically stained for TGF- $\beta$ (40x). A) Group I: Diffuse staining in TGF- $\beta$-positive cells of the spinal cord. B) Group II: Weak staining in TGF- $\beta$-positive cells (arrow).
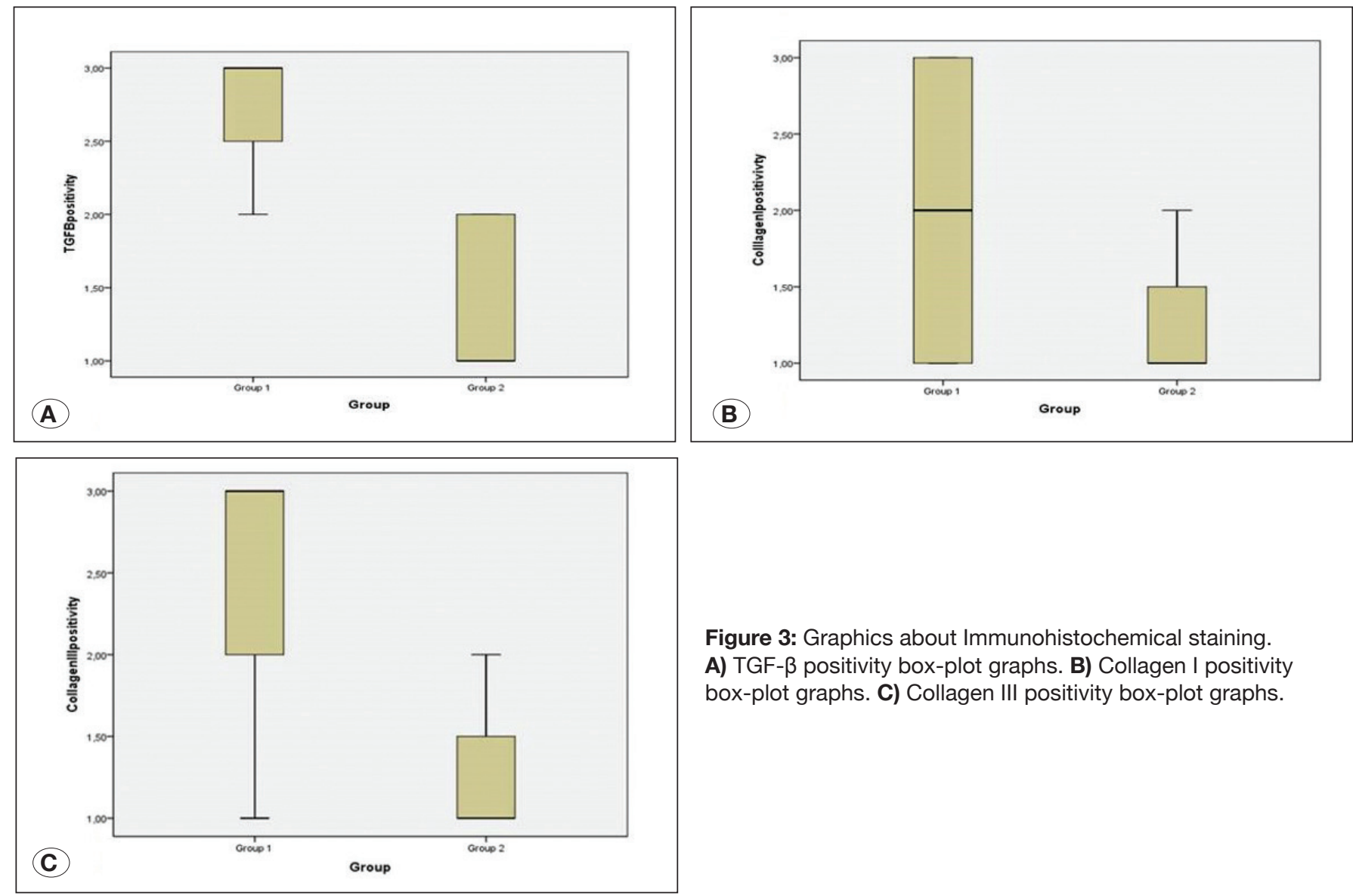

Figure 3: Graphics about Immunohistochemical staining. A) TGF- $\beta$ positivity box-plot graphs. B) Collagen I positivity box-plot graphs. C) Collagen III positivity box-plot graphs. 
haemorrhages. In addition, the extent of post-operative scar formation may vary depending on the laminectomy technique, infections, amount of bone removed and anatomical region of the spinal vertebrae $(1,9,11,19,21)$. Especially, fibrous connective tissues adjacent to the laminar traumas are activated to repair the wound as confirmed by the evidence that fibroblast proliferation and inflammatory cytokine release are greatly increased. Fibroblasts are impelled to excessively proliferate and produce collagens (mainly collagen type I) by the increased inflammatory mediators (TGF- $\beta 1$ and others) (12). Excessive TGF- $\beta 1$ stimulates fibroblast proliferation

Table IV: Assessments of Collagen-III Positivity Scores of All Groups

\begin{tabular}{lc} 
Groups & $\begin{array}{c}\text { Collagen-III positivity scores } \\
\text { (Median } \pm \text { Std. Dev.) }\end{array}$ \\
\hline Group 1 & $2.5 \pm 0.76$ \\
\hline Group 2 & $1.25 \pm 0.46^{\mathrm{a}}$ \\
\hline
\end{tabular}

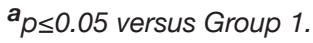

and differentiation to myofibroblasts, while it accelerates the deposition of extracellular matrix (13). As a result, if fibroblast stimulation increases, excessive epidural fibrosis occurs $(5,14,20,36)$. Therefore, PLEF can cause compression and/ or restriction of nerve root mobility or dural compression and spinal canal stenosis, and it can lead to persistent back and radicular leg pain, as well as limited mobility (35). Moreover, PLEF is a major challenge in secondary spine surgery. The principal finding in the present study showed that more epidural fibrosis was found in Group I.

It is intended to carry out an experimental investigation of the effect of high temperature on the epidural space, which is thought to influence this process. The release of fibroblasts and fibroblast-secreted chemicals into the surgical field has been identified as the main cause of PLEF formation (11). Excessive heat is an important cause of tissue injury. It has been found that there are few studies on the side effects of electrocautery devices on different systems and organs. Electrocautery devices are used to provide haemostasis with thermal effects in many surgical interventions. However, they can lead to direct tissue damage, necrosis and subsequent
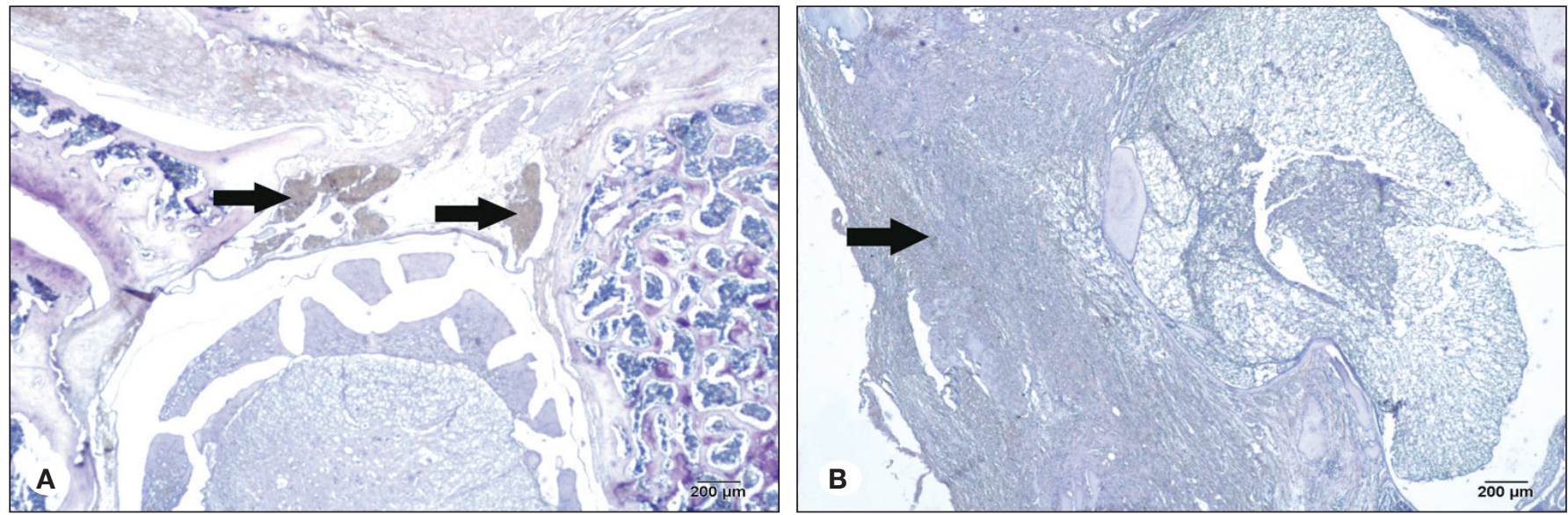

Figure 4: Photographs of rat spinal cords immunohistochemically stained for collagen I (40x). A) Group I: Diffuse staining in collagen I-positive cells of the spinal cord. B) Group II: Weak staining in collagen I-positive cells (arrow).
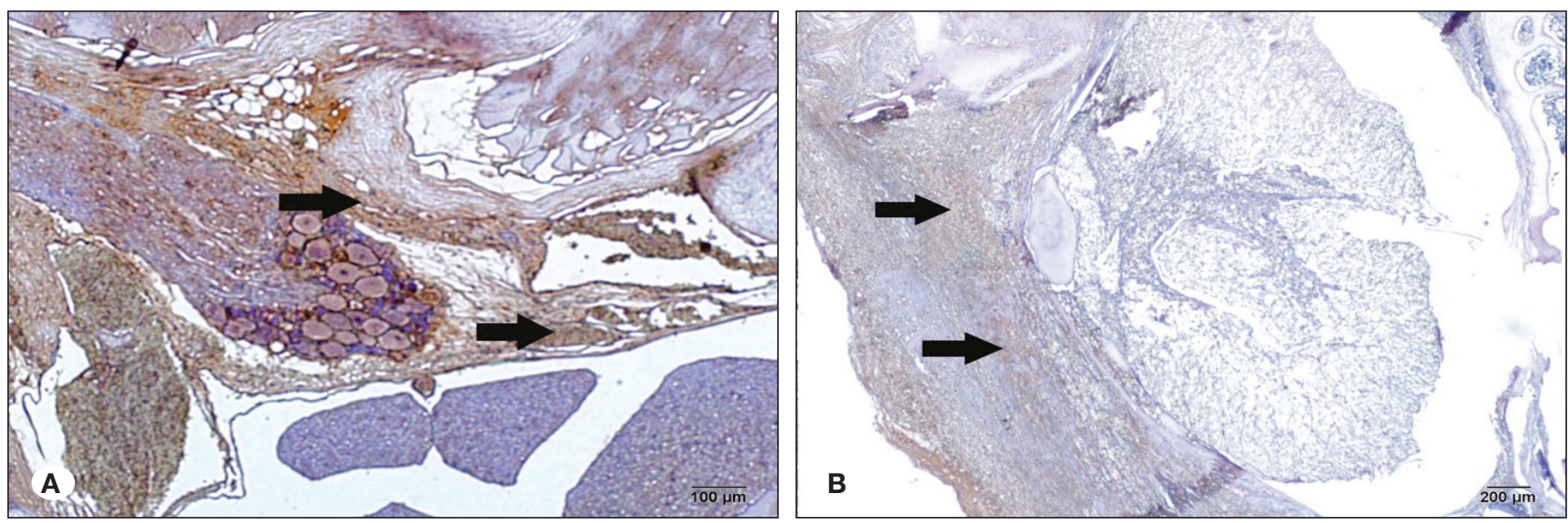

Figure 5: Photographs of rat spinal cords immunohistochemically stained for collagen III (40x). A) Group 1: Diffuse staining in collagen III-positive cells of the spinal cord. B) Group II: Weak staining in collagen III-positive cells (arrows). 
fibrosis and granulation via the thermal effect $(4,13,18,22-24$, 27). It has been discussed that excessive coagulation with bipolar cauterisation may cause a similar effect, even with small and thin probes. Surgical instruments that use thermal energy cause some changes in tissues, depending on the high temperature. The duration and amount of energy used can cause effects at different levels. The destruction that occurs within the tissue is related to the increase in the temperature. Burn injury, also known as combustion injury, can stop the blood flow in the tissue by activating inflammatory agents. Thus, it prevents the normal healing process. Severe damage at the cellular level can cause further scattering of chemical cytokines, especially fibroblasts, in the surgical field (20). In addition, excessive release of neuropeptides, such as substance-P from damaged nerve endings, may lead to further angiogenesis, and eventually, hypertrophic scarring in the wound $(4,20)$. In addition, in a similar experimental study, bipolar cauterisation has been shown to produce histopathologic side effects on the sciatic nerve, even at low voltages (18). Another study using a porcine model did not investigate the fibrotic effect of bipolar electrocautery, but instead, demonstrated its potential damage mechanisms of neuronal tissue. Another model investigated the direct effect of two different cautery techniques on the spinal cord tissue, which showed that the high thermal effect can cause burning and carbonisation of the tissues (27). Especially, carbonisation residues are often observed in granulomatous lesions (4). Anatomical locations of granulomas support the presence of common pathogenesis with sites exposed to electrocautery, suggesting that carbonisation also has an effect that increases PLEF.

Another study reported that most of the complaints in the cases resulting from low voltage injury are associated with fibrosis, which is formed around the peripheral nerves (32). It has been reported that perineural fibrosis is especially encountered in all decompressive surgical procedures for the treatment of these patients $(32,35)$. The same result was encountered in our study.

In another study, non-contact argon plasma coagulation (APLC), which has been widely used in recent years for haemostasis during intra-peritoneal surgery, has been compared with monopolar and bipolar electrocautery devices in terms of the potential formation of fibrosis. This study also demonstrates that APLC is potentially more likely to bring about adhesion due to its high energy consumption (31). These studies showed the correlation between excessive use of electrocautery devices and the formation of postoperative fibrosis. Our experimental study has also shown that there is a correlation between excessive or un-proportional use of the bipolar electrocautery device and excessive fibrosis formation.

\section{Strengths of the Study}

The strength of this study was that it was the first investigation of the effect of bipolar electrocautery devices on the formation of fibrosis as an undesirable effect in the epidural area in a rat experiment. In addition, our study differs from other studies in that epidural fibrosis in the rat model was evaluated not only histopathologically but also with the TGF- $\beta$, collagen I and collagen III immunochemical stains. There are very few studies in the literature evaluating epidural fibrosis by the immunostaining method.

Previous studies have indicated a focus on the prevention of epidural fibrosis, especially via the inhibition of TGF- $\beta$ formation. The immunostaining method has been reported to be used for this purpose in limited studies $(12,17,34)$. Collagen types I and III constitute $90 \%$ of all the collagens in the human body. These are the main structural proteins, especially in the bones, tendons and ligaments. Therefore, collagen I and III stains were used directly in the present experiments.

TGF- $\beta 1$ is one of the most important factors initiating epidural fibrosis. Thus, an increase in TGF- $\beta$ levels leads to a more pronounced epidural fibrosis $(30,34)$. Sections from both groups were stained with TGF- $\beta$ for determining the levels of epidural fibrosis in the groups. In this study, we showed that increased TGF- $\beta$ levels were demonstrated by the immunochemical staining method in group I (Figure 2A, B). It is also understood, although not directly histologically proven, that a higher level of bipolar electro-cauterisation-induced carbonisation reaction in group I may lead to epidural fibrosis.

The effects of haemostatic agents on epidural fibrosis were evaluated in two different experimental studies about spinal surgery in the literature. Epidural fibrosis and chronic inflammatory cell density were found to be significantly lower in the haemostatic agent groups in both studies $(2,10)$. This study demonstrated the importance of limited to use the bipolar device during haemostasis in reducing epidural fibrosis in spinal surgery on an experimental laminectomy model in rats. However, excessive use of bipolar electrocautery can result in exaggerated epidural fibrosis. Our study supports these results because it demonstrates the effect of exaggerated tissue damage during haemostasis with bipolar electrocautery.

\section{Weaknesses and Limitations of the Study}

A weakness of the study is that the experimental rat model used is morphologically small. The fact that the rats were smaller than the other experimental animals made the surgical intervention difficult. The need for haemostasis in each rat was considered weak. It has been attempted to standardise this. In addition, this study still had some limitations. First, calculation of sample size is one of the important issues in the design of experimental rat studies. If a researcher selects too few animals, it may lead to missing a significant difference even if it exists in the population; if too many animals are selected, it may lead to unnecessary wastage of resources and ethical issues. The second important issue is that the model may not fully mimic human physiology. The third and most important issue is that the efficacy of bipolar electrocautery in the laminectomy model was evaluated at the end of only 28 days. We do not know the change of epidural fibrosis occurring at the end of a longer period.

\section{Importance of the Present Study}

The present study shows that the damage induced by the burning of connective tissues adjacent with bipolar electrocautery to the neural tissue begins excessive or 
exaggerated epidural fibrosis reactions in a rat model. In addition, it represents the first investigation of the effect of bipolar electrocautery on postoperative epidural fibrosis in a rat model.

\section{Explicit Recommendations for the Next Step}

The ongoing clinical complaints of our patients suggest that there is a need for further investigation of the effects of surgical techniques and methods for haemostasis in wound healing. New therapeutic agents should be used in novel experiments for treating epidural fibrosis caused by the use of a bipolar cautery device. In the next step, we plan to investigate this subject again with other therapeutic agents.

\section{CONCLUSION}

Excessive bipolar electrocautery use can be related to the formation of epidural fibrosis, which was highlighted by the immunohistochemical data provided by the present study. Accordingly, our recommendation is to limit use of this technique during spine surgery for haemostasis.

\section{ACKNOWLEDGMENTS}

The Recep Tayyip Erdogan University scientific research community provided financial support in the form of funding for the purchase of experimental materials. The sponsor had no role in the design or performance of this research.

The authors would like to thank doctor Paolo Frassanito (Department of Neurosurgery, Catholic University Medical School) for his invaluable advice and revision, and Ibrahim Yerebakan (Recep Tayyip Erdogan University) for language editing.

\section{REFERENCES}

1. Alkalay RN, Kim DH, Urry DW, Xu J, Parker TM, Glazer PA: Prevention of postlaminectomy epidural fibrosis using bioelastic materials. Spine (Phila Pa 1976) 28(15):1659-1665, 2003

2. Altun I: An experimental study of histopathologic effects of hemostatic agents used in spinal surgery. World Neurosurg 90:147-153, 2016

3. Awad JN, Kebaish KM, Donigan J, Cohen DB, Kostuik JP: Analysis of the risk factors for the development of postoperative spinal epidural haematoma. J Bone Jt Surg $\mathrm{Br}$ 87(9):1248-1252, 2005

4. Beriat GK, Akmansu SH, Ezerarslan H, Dogan C, Han U, Saglam M, Senel OO, Kocaturk S: The comparison of thermal tissue injuries caused by ultrasonic scalpel and electrocautery use in rabbit tongue tissue. Bosn J Basic Med Sci 12(3):151157, 2012

5. Branton $\mathrm{MH}$, Kopp JB: TGF-beta and fibrosis. Microbes Infect 1(15):1349-1365, 1999

6. Cemil B, Tun K, Kaptanoglu E, Kaymaz F, Cevirgen B, Comert A, Tekdemir I: Use of pimecrolimus to prevent epidural fibrosis in a postlaminectomy rat model. J Neurosurg Spine 11(6):758763, 2009
7. Chen RK, Than KD, Wang AC, Park P, Shih AJ: Comparison of thermal coagulation profiles for bipolar forceps with different cooling mechanisms in a porcine model of spinal surgery. Surg Neurol Int 4:113, 2013

8. Coskun E, Suzer T, Topuz O, Zencir M, Pakdemirli E, Tahta K: Relationships between epidural fibrosis, pain, disability, and psychological factors after lumbar disc surgery. Eur Spine $J$ 9(3):218-223, 2000

9. de Tribolet N, Porchet F, Lutz TA, Gratzl O, Brotchi J, van Alphen HA, van Acker RE, Benini A, Strommer K, Bernays RL, Goffin J, Beuls EAM, Ross JS: Clinical assessment of a novel antiadhesion barrier gel: Prospective, randomized, multicenter, clinical trial of ADCON-L to inhibit postoperative peridural fibrosis and related symptoms after lumbar discectomy. Am J Orthop (Belle Mead NJ) 27(2):111-120, 1998

10. Demirel E, Yildiz K, Cadirci K, Aygun H, Senocak H: Effect of platelet-rich fibrin on epidural fibrosis and comparison to ADCON $^{\circledR}$ Gel and hyaluronic acid. Acta Orthop Traumatol Turc 52(6):469-474, 2018

11. Erdogan $H$, Kelten $B$, Tuncdemir M, Erturkuner SP, Uzun $H$, Karaoglan A: Hemostasis vs. epidural fibrosis?: A comparative study on an experimental rat model of laminectomy. Neurol Neurochir Pol 50(5):323-330, 2016

12. Fan X, Chen J, Shi D, Jia J, He J, Li L, Lei T, Chen X: The role and mechanisms of action of SIRT6 in the suppression of postoperative epidural scar formation. Int $\mathrm{J}$ Mol Med 37(5):1337-1344, 2016

13. Fisekcioglu E, Dumlu A, Ozdemir N: A histopathological study of wound healing in rabbit oral mucosa after incisions made with electrocautery or CO2 laser. J Laser Appl 5(4):225-230, 2005

14. Gurer B, Kahveci R, Gokce EC, Ozevren H, Turkoglu E, Gokce A: Evaluation of topical application and systemic administration of rosuvastatin in preventing epidural fibrosis in rats. Spine J 15(3):522-529, 2015

15. He Y, Revel M, Loty B: A quantitative model of postlaminectomy scar formation. Effects of a nonsteroidal antiinflammatory drug. Spine (Phila Pa 1976) 20(5):557-580, 1995

16. Hoyland JA, Freemont AJ, Denton J, Thomas AM, McMillan $\mathrm{JJ}$, Jayson MI: Retained surgical swab debris in postlaminectomy arachnoiditis and peridural fibrosis. J Bone Joint Surg $\mathrm{Br}$ 70(4):659-662, 1988

17. Hsu DZ, Jou IM: 1,4-Butanediol diglycidyl ether-cross-linked hyaluronan inhibits fibrosis in rat primary tenocytes by downregulating autophagy modulation. J Mater Sci Mater Med 27(5):1-7, 2016

18. Karalezli N, Koktekir E, Yildirim S, Toy H, Oz M, Yuceturk A: The effects of electrocautery on peripheral nerve: An experimental study. J Neurol Surg A Cent Eur Neurosurg 77(3):201-206, 2016

19. Kasimcan MO, Bakar B, Akta S, Alhan A, Yilmaz M: Effectiveness of the biophysical barriers on the peridural fibrosis of a postlaminectomy rat model: An experimental research. Injury 42(8):778-781, 2011 
20. Killeen T, Kamat A, Walsh D, Parker A, Aliashkevich A: Severe adhesive arachnoiditis resulting in progressive paraplegia following obstetric spinalanaesthesia: $A$ case report and review. Anaesthesia 67(12):1386-1394, 2012

21. Kotil K: Closed drainage versus non-drainage for singlelevel lumbar disc surgery: Relationship between epidural hematoma and fibrosis. Asian Spine J 10(6):1072-1078, 2016

22. Kraemer B, Rothmund R, Fischer K, Scharpf M, Smaxwil L, Enderle MD, Wallwiener C, Neugebauer A: A prospective experimental study to investigate the peritoneal adhesion formation of argon plasma coagulation (APC) versus a novel aerosol plasma in a rat model. Surg Innov 21(4):389-397, 2014

23. Lipscomb GH, Givens VM: Preventing electrosurgical energyrelated injuries. Obstet Gynecol Clin North Am 37(3):369-377, 2010

24. Livaditis GJ: Comparison of monopolar and bipolar electrosurgical modes for restorative dentistry: A review of the literature. J Prosthet Dent 86(4):390-399, 2001

25. Lucas AJ: Failed back surgery syndrome: Whose failure? Time to discard a redundant term. Br J Pain 6(4):162-165, 2012

26. Mercantepe T, Unal D, Selli J, Mercantepe F, Unal B, Karabiyik TN: Protective effects of estrogen and bortezomib in kidney tissue of post-menopausal rats: An ultrastructural study. Ren Fail 38(7):1129-1135, 2016

27. Moreira CM, Amaral E: Use of electrocautery for coagulation and wound complications in caesarean sections. Sci World J 2014:602375, 2014

28. Nishida K, Kakutani K, Maeno K, Takada T, Yurube T, Kuroda $\mathrm{R}$, Kurosaka M: Efficacy of hemostasis for epidural venous plexus and safety for neural structure using soft coagulation system in spinal surgery a laboratory investigation using a porcine model. J Spinal Disord Tech 26(7):E281-E285, 2013
29. Ouaissi M, Gaujoux S, Veyrie N, Deneve E, Brigand C, Castel B, Duron JJ, Rault A, Slim K, Nocca D: Post-operative adhesions after digestive surgery: Their incidence and prevention: Review of the literature. J Visc Surg 149(2):e104-114, 2012

30. Pereira P, Avelino A, Monteiro P, Vaz R, Castro-Lopes JM: New insights from immunohistochemistry for the characterization of epidural scar tissue. Pain Physician 17(5):465-474, 2014

31. Selli J, Unal D, Mercantepe F, Akaras N, Kabayel R, Unal B, Atilay $\mathrm{H}$ : Protective effects of beta glucan in brain tissues of post-menopausal rats: A histochemical and ultra-structural study. Gynecol Endocrinol 32(3):234-239, 2016

32. Smith MA, Muehlberger T, Dellon AL: Peripheral nerve compression associated with low-voltage electrical injury without associated significant cutaneous burn. Plast Reconstr Surg 109(1):137-144, 2002

33. Turkoglu E, Tuncer C, Dinc C, Serbes G, Oktay M, Sekerci $Z$ : The effect of etanercept on spinal epidural fibrosis in a postlaminectomy rat model. Turk Neurosurg 24(4):506-511, 2014

34. Yang L, Tang J, Chen H, Ge D, Sui T, Que J, Cao X, Ge $Y$ : Taurine reduced epidural fibrosis in rat models after laminectomy via downregulating EGR1. Cell Physiol Biochem 38(6):2261-2271, 2016

35. Yong-Hing K, Reilly J, de Korompay V, Kirkaldy-Willis WH: Prevention of nerve root adhesions after laminectomy. Spine (Phila Pa 1976) 5(1):59-64, 1980

36. Zhu L, Ni B, Liu J, Yang J, Guo Q, Zhou W: Hydroxycamptothecin liposomes inhibit collagen secretion and induce fibroblast apoptosis in a postlaminectomy rabbit model. Eur J Orthop Surg Traumatol 23 Suppl 1:S85-91, 2013 